\title{
Androgens and masculinization of genitalia in the spotted hyaena (Crocuta crocuta). 3. Effects of juvenile gonadectomy
}

\author{
S. E. Glickman ${ }^{1}$, E. M. Coscia ${ }^{1}$, L. G. Frank ${ }^{1}$, P. Licht ${ }^{2}$, M. L. Weldele ${ }^{1}$ \\ and C. M. Drea ${ }^{1}$ \\ ${ }^{1}$ Department of Psychology, University of California, Berkeley, CA 94720; and \\ ${ }^{2}$ Department of Integrative Biology, University of California, Berkeley, CA 94720, USA
}

\begin{abstract}
Studies involving the administration of anti-androgens to spotted hyaenas during fetal development have raised questions concerning the precise contributions of steroids to phallic growth in these animals. If gonadal androgens promote postnatal penile growth in males, the following would be expected: (a) a period of accelerated growth accompanying achievement of puberty, and (b) a marked reduction in adult penile size and density of penile spines after gonadectomy. If a similar androgenic pubertal process stimulates clitoral growth in these highly 'masculinized' hyaenas, parallel observations in females would be expected; however, the role of oestrogens in accounting for female-typical clitoral development would also have to be considered. The results of the present study suggest a limited role, if any, for androgenic stimulation of phallic growth. That is, penile growth was greater during the 10 month period preceding puberty, than during an 18 -month period that included the traditional increase in pubertal androgens. In addition, pre-pubertal castration had minimal effects on penile length, diameter, or the presence of penile spines. In females, most clitoral growth also occurred before puberty, although pre-pubertal ovariectomy produced significant reductions in clitoral diameter and the elasticity of the urogenital meatus. These feminine characteristics, which normally distinguish the female from the male phallus in this species, were partially restored by a brief period of oestrogen administration. Both sexes displayed erections many years after pre-pubertal castration. The results of the present study suggest that postnatal phallic growth is largely independent of gonadal steroids, with oestrogenic facilitation of female-typical clitoral characteristics in spotted hyaenas.
\end{abstract}

\section{Introduction}

The extraordinarily masculinized external genitalia of the female spotted hyaena are typically attributed to the actions of naturally circulating androgens (Matthews, 1939; Racey and Skinner, 1979; Glickman et al., 1987; Licht et al., 1992). In particular, formation of the penile clitoris and fused scrotum have been ascribed to androgens circulating during fetal life, either derived from the fetal ovary (Lindeque and Skinner, 1982) or transferred to the fetus from the placenta (Licht $e t$ al., 1992. 1998; Yalcinkaya et al., 1993). Examination of male and female hyaenas whose mothers were treated with antiandrogens during pregnancy revealed that there were substantial modulating effects of naturally circulating androgens on genital development in both sexes. However, all hyaenas born to anti-androgen treated females had a well-developed penis or pseudopenis and a fused scrotum or pseudoscrotum (Drea et al., 1998). When pregnant female rodents and dogs are exposed to such treatments, their male offspring display an external vaginal opening and a penis of much-reduced size, with a urethra terminating near the base of the organ (Neumann et al.,

Received 14 August 1997.
1970; Neri et al., 1972). In hyaenas, anti-androgen treatment merely exaggerated the normal species-typical phallic dimorphism in the 'feminine' direction. These findings raised the possibility that the essential formation of the penile clitoris of the spotted hyaena was an androgen-independent event. Assuming that there is such an androgen-independent mechanism of genital formation in this species, it might also be anticipated that it would operate during postnatal life to promote genital growth in the absence of androgens.

The aim of the present study was to pursue this line of argument and to re-examine the question of normal clitoral and penile growth in hyaenas and the effects of gonadectomy on such growth. The normal influence of androgens on postnatal penile growth is inferred from: (a) an accelerated period of penile growth during puberty, accompanying enhanced androgen production (Schonfeld, 1943); and (b) the reduction in genital growth exhibited by prepubertally castrated male mammals, compared with normal males or adult castrates (for example, Beach, 1970). Furthermore, in species that display spines or papillae on the glans penis (for example, rats and dogs), castrates exhibit a reduction in the density of spines or papillae, or both, on the glans, with a much larger effect occurring in prepubertally castrated subjects (Beach and 
Levinson, 1950; Beach and Westbrook, 1968; Beach, 1970; Sachs et al., 1984).

If gonadal androgens are responsible for the postnatal growth of the clitoris and penis in spotted hyaenas, a marked acceleration in growth associated with achievement of puberty and concomitant increments in gonadal steroids would be expected. In addition external genitalia that are much reduced in size, with fewer spines, would be expected in hyaenas gonadectomized before puberty. However, if postnatal genital growth is a largely androgen-independent phenomenon, a pattern of clitoral-penile growth that did not reveal any acceleration accompanying achievement of puberty, and no effects of prepubertal gonadectomy on testosterone-related growth processes would be anticipated.

Those aspects of phallic growth that are more prominent in female than male hyaenas (that is, a large, elastic urogenital meatus and enhanced diameter of the glans) might be expected to be features of growth facilitated by pubertal oestrogens. The nipples and the urogenital meatus of female hyaenas show accelerated growth associated with pubertal steroids, with ovariectomy eliminating that pattern of accelerated growth (Glickman et al., 1992). However, since ovariectomy removes both oestrogens and $\Delta^{4}$-androstenedione (androst-4-ene3,17 , dione), it has not been clear if the observed effects are due to deletion of oestrogen per se. The present study provides additional data on the effects of ovariectomy and subsequent treatment with exogenous oestradiol on clitoral morphology and nipple development.

\section{Materials and Methods}

\section{Animals}

Genital development was studied in intact and prepubertally gonadectomized spotted hyaenas (Crocuta crocuta) maintained at the Field Station for Behavioral Research of the University of California, Berkeley. Intact animals included 25 females and 20 males. Gonadectomized animals included six ovariectomized females (one at 30 days, two each at 5 and 6 months, and one at 11 months) and four castrated males (one at 37 days, two at 6 months, and one at 10 months). Such surgery eliminates almost all plasma testosterone and approximately $90 \%$ of plasma $\Delta^{4}$-androstenedione (Glickman et al., 1992). The subjects ranged from 7 months to 12 years of age.

\section{Genital measurements, body size and phallic appearance in hyaenas}

Development was monitored during routine physical examinations of anaesthetized animals (2.5-4.0\% isoflurane; Solvay Animal Health, Mendota Heights, MN) conducted approximately every month during the first year, biannually during adolescence, and annually in adulthood. The genital measures obtained in Drea et al. (1998) were also obtained in the present study, and in the same manner; however, only three of those measures are reported here.

Glans diameter measurements were taken routinely starting early in the research programme and are, therefore, considered the primary data set.
Phallus length measures have been obtained only within recent years and consequently provide a less extensive data set. Length estimates require an increase in tension as the animal matures. An animal's first estimate, taken at 2 months of age, used a tension of $150 \mathrm{~g}$. By 6 months of age, the same tension is less 'challenging' as the phallus has increased in diameter and provides more resistance (Drea et al., 1998); therefore, at I year of age and thereafter, the tension was increased to $500 \mathrm{~g}$. Subjectively, the tension used at each age selected for the present analyses (see below) stretched the phallus to its full potential. Consequently, we treat this measure as a continuous variable in making comparisons across age intervals.

The stretched length of the urogenital meatus is reported for gonadectomized females at a tension of $50 \mathrm{~g}$.

Body length was measured from the tip of the nose to the base of the tail.

Erections were photographed while males and females were engaged in greeting ceremonies.

The density of papillae and spines on the glans was estimated by counting the number of spines encompassed within a $36 \mathrm{~mm}^{2}$ template opening. A value for each individual was based on an average of counts taken of four different regions. In addition, any qualitative differences in appearance (for example, relative size, colour) were noted.

Nipple diameter was measured from the lateral to the medial edge, at the point of maximum distance, and values are reported as the average of the left and right nipples.

\section{Oestrogen replacement in ovariectomized hyaenas}

Five adult ovariectomized female hyaenas were administered oral oestradiol each day for a period of 6 weeks $\left(4 \mathrm{mg}\right.$ day $^{-1}$, Estrace $^{\mathrm{B}}$, Mead Johnson Laboratories, Princeton, NJ). The average dose used was $0.07 \mathrm{mg}$ oestradiol $\mathrm{kg}^{-1}$, which is at the high end of the range used in human clinical practice for the treatment of ovarian failure (Physicians' Desk Reference, 1997).

\section{Averaging data within age periods}

Guidelines for selecting appropriate age periods for averaging early developmental data were based on the following information. (1) Achievement of puberty is conventionally assumed to occur at approximately 24 months of age in males and 36 months of age in females. (2) In our colony, both sexes typically exhibit adult concentrations of gonadal steroids by 30 months of age (Glickman et al., 1992) and the average age at first conception was 33 months of age (Licht et al., 1992). (3) Since studies of normal female development are complicated by the effects of copulation and birth on the morphology of the external genitalia (Frank and Glickman, 1994; Frank et al., 1995), complete assessment in intact animals is limited to the first 3 years of life. Thus, for comparison of body growth and genital measures, three 2 month age intervals were selected: an 'infant' period (2-4 months), which involved the earliest age at which measures could be taken from the developing genitalia; a 'juvenile' period (12-14 months), which tapped both sexes before an increase in pubertal steroids; and a 'young adult' stage (30-32 months), when all hyaenas would have 
displayed mature steroid profiles, but before females engaged in copulatory behavior (Glickman et al., 1992).

For the more recently obtained measures of phallic length and spine density, the developmental data sets are limited. Therefore, the long-term effects of gonadectomies were assessed by focusing examination on the oldest animals in the colony, aged 4 years or older. This selection criterion included control females that did not conceive. All lines of evidence suggest that little change in genital development occurs after 2 years of age (see below).

\section{Statistical analyses}

As spotted hyaenas are long-lived, any given age category in the present study comprised different animals, with sample sizes varying across ages. Therefore, independent analyses were conducted for each of the three age intervals (that is, infancy, the juvenile period, and early adulthood). One-way ANOVAs, followed by Scheffe's test to resolve significant effects, were used to assess sex and treatment effects on the measures of body growth and glans diameter. Because of the small sample of gonadectomized subjects, analyses of phallic length were limited to Student's $t$ tests comparing intact males and females. For all three measures, a smaller sample of control males and females were consistently represented at all three ages. For these subsets, difference scores were calculated between the first two age categories and the last two age categories, and these values were compared using paired $t$ tests.

One-way ANOVAs (using means for individuals with repeated measures), followed by Scheffe's test for paired comparisons between groups, were performed to compare phallic length and spine density in older hyaenas; however, the castrate condition for spine density $(n=1)$ was excluded from analysis. For comparisons of clitoral glans diameter and length of the stretched urogenital meatus in five older ovariectomized females undergoing oestrogen replacement, $t$ tests were perfomed, comparing pre-oestradiol baseline measures with measures obtained after 6 weeks of replacement therapy.

\section{Results}

\section{Development in intact hyaenas: infancy through early adulthood}

Glans diameter, phallic length, and body length. The pattern of normal growth on two genital measures, in comparison with a measure of stature, are shown in male and female spotted hyaenas at three age intervals (Fig. 1). There was a sex difference in the glans diameter of intact animals at the later age intervals (infants: $t_{32}=1.96, P=0.059$; juveniles: $F_{3,20}=13.12, \quad P<0.0001 ; \quad$ young adults: $\quad F_{3,27}=23.89$, $P<0.0001$ ), with female values exceeding those of males $(P<0.001$, Fig. Ia), as described by Drea et al. (1998). Similarly, there was a sex difference in phallic length at the earlier intervals (infants: $t_{7}=5.86, P<0.001$; juveniles: $t_{5}=2.63$, $P<0.05$; young adults: $t_{4}=1.22, P>0.20$ ), with male values exceeding female values (Fig. Ib). However, there was no sex difference in the pattern of body growth at any age (infants: $t_{26}=0.03, P>0.95$; juveniles: $F_{3,27}=2.44, P>0.08$; young adults: $F_{3,28}=1.32, P<0.25$; Fig. 1 c).
In intact males, $94 \%$ of growth in glans diameter, $82 \%$ of growth in phallic length, and $77 \%$ of skeletal growth occurred well before puberty, that is, between the first and second age intervals (Fig. 1). For the subsets of males with repeated measures across all age intervals, paired $t$ tests on difference scores revealed greater increases from the first to the second interval (4-12 months) than from the second to the third interval (14-30 months) (glans diameter: $t_{8}=6.81, P<0.0001$; phallic length: $t_{3}=5.68, P<0.02$; body length: $t_{8}=11.65$, $P<0.0001$ ).

In intact females, skeletal growth was largely completed $(82 \%)$ during the first year of life, as it was in intact males (Fig. 1c). These data suggest a slightly different pattern of phallic growth in female hyaenas. Although $72 \%$ of growth in the diameter of the glans clitoridis and $66 \%$ of growth in clitoral length was achieved by 1 year of age (Fig. 1a,b), there was a substantial increment during the subsequent pubertal period. The sample sizes for subsets of females with repeated age measures were small (or unavailable), but they tended to show the same pattern as in males, that is, greater increases from the first to the second interval than from the second to the third interval, although these did not reach statistical significance (phallic diameter: $t_{3}=1.73, P=0.18$; body length: $\left.t_{2}=3.76, P=0.06\right)$.

\section{Genital measures and phallic appearance in older, intact hyaenas}

Phallic length. The normal adult pattern for phallic length, a genital measure traditionally described as androgendependent, in male and female spotted hyaenas aged 4 years or older, is shown (Fig. 2). As in younger animals, there is a significant sex difference $\left(F_{3,22}=9.06, P<0.0005\right)$, with intact male values exceeding those of intact females $(P<0.005$, Fig. 2).

Spine density. The presence of spines and papillae, although typically a masculine feature (for example, in rats and dogs; Beach, 1970; Sachs et al., 1984), has been reported in the females of certain lemuriform species that display a peniform clitoris (Ioannou, 1971). Intact male and female spotted hyaenas both display spines and papillae on their glans; however, a sex difference in density $\left(F_{2,19}=5.88, P<0.02\right)$ was observed, with male hyaenas having more spines than females $(P<0.02$; Fig. 3).

\section{Development in gonadectomized hyaenas: infancy through early adulthood}

Glans diameter, phallic length and body length. Patterns of genital growth and body growth in gonadectomized animals indicate very small effects of withdrawing gonadal hormones well before puberty (Fig. 1). Compared with intact males, castrated males showed no differences in glans diameter $(P>0.73$; Fig. 1a) or body length ( $P>0.95$; Fig. $I C)$, at any age. Similarly, compared with intact females, ovariectomized females showed no difference in body length $(P>0.64$; Fig. $1 c)$, but their glans diameter was significantly smaller in early adulthood $(P<0.0005$; Fig. 1a). 
Genital measures and phallic appearance in older, gonadectomized hyaenas

Phallic length. Prepubertal gonadectomies had virtually no effect on phallic length, measured in adulthood (Fig. 2). Penile length in two prepubertally castrated males was within the
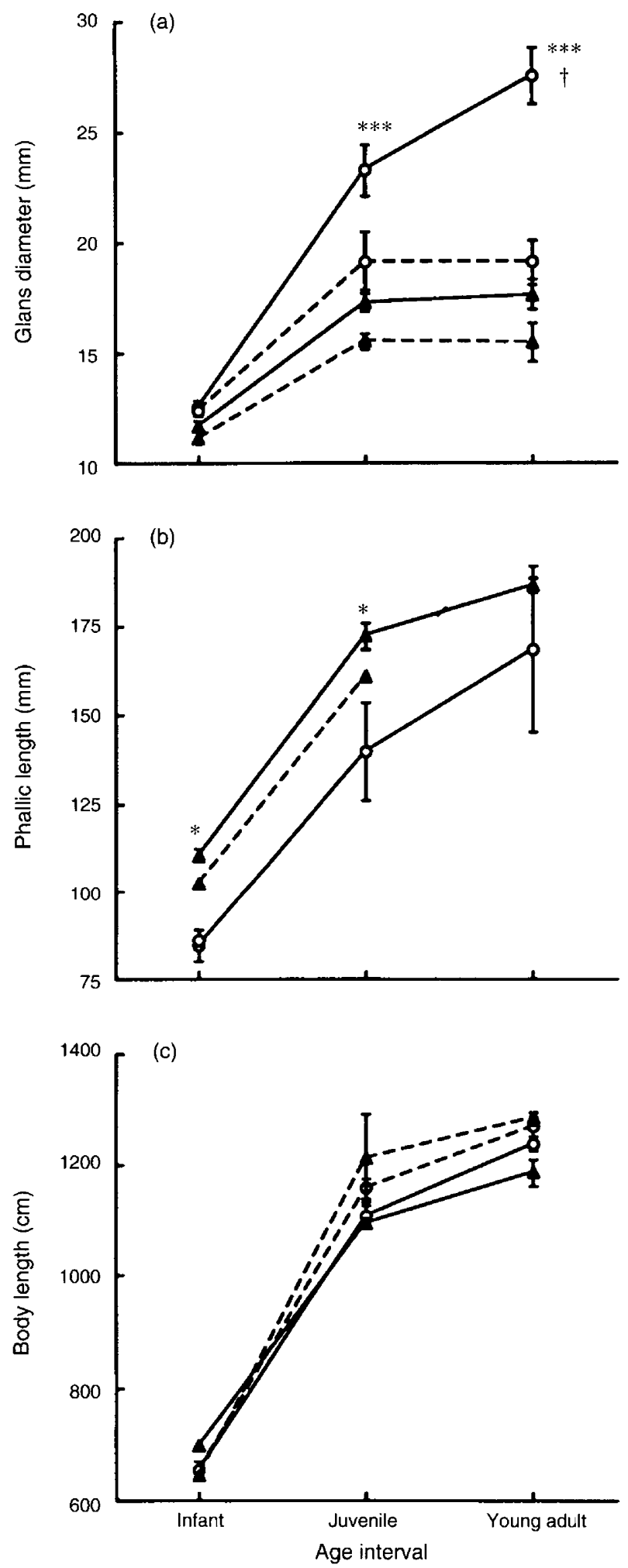

range of normal control males $(P>0.10)$. Ovariectomy had no effect on clitoral length in adult females $(P>0.10)$.

Erections. A male castrated at 37 days of age was capable of achieving a 'normal' erection at 2 years of age (Fig. 4a). One male, castrated at 6 months of age, displayed a normal erection more than 10 years after surgery (Fig. 4b). This long-term castrate had a well-defined glans penis, marked by the presence of penile spines. Prepubertally ovariectomized females also displayed normal erections years after surgery.

Spine density. Prepubertal gonadectomies had virtually no effect on spine density (Fig. 3). The single castrated male for which spine data were available was observed at II years of age (Fig. 4b). Although this animal was excluded from statistical analyses, it displayed a density of spines that fell within the range of intact males (Fig. 3). Nevertheless, this male possessed spines that appeared smaller and finer than those of agematched controls. In comparison with intact females, ovariectomized adult hyaenas retained a normal number of spines on their glans $(P>0.60$, Fig. 3).

\section{Oestrogen replacement in ovariectomized hyaenas}

The changes in genital and nipple measurements accompanying exposure to oestradiol in prepubertally ovariectomized spotted hyaenas are shown (Fig. 5). In adulthood, ovariectomized females showed a significant increase in clitoral glans diameter $\left(t_{4}=3.03, P<0.05\right.$; Fig.5a), length of the stretched urogenital meatus $\left(t_{4}=3.86, P<0.05\right.$; Fig. $\left.5 \mathrm{~b}\right)$, and nipple diameter $\left(t_{4}=6.04, P<0.005\right.$; Fig. $\left.5 \mathrm{c}\right)$ after 6 weeks of oestradiol replacement.

\section{Discussion}

The results of the present study indicate that the rate of penile growth in spotted hyaenas actually decelerates during the pubertal period. This contrasts with, for example, primates (Plant, 1988), including men (Schonfeld, 1943; Tanner, 1978). In men, the length and circumference of the penis increase only $25 \%$ during the period between $I$ and 11.5 years of age, whereas $75 \%$ of growth occurs between 11.5 and 17 years of age, presumably because of the stimulating effects of gonadal testosterone accompanying puberty (Schonfeld, 1943; Figs 5 and 6). In hyaenas, penile length, glans diameter, and

Fig. 1. Mean \pm SEM (a) glans diameter, (b) phallic length and (c) body length in young spotted hyaenas at age intervals representing infancy, the juvenile period, and young adulthood. For intact males ( $-\boldsymbol{\Lambda}-)$, the sample sizes at each 2 month age interval were $10-16,4-5$ and 10-14, for measures (a), (b) and (c), respectively. Similarly, for intact females (- $\mathrm{O}-$ ), sample sizes were 9-18 (a), 2-4 (b) and 11-14 (c). For castrated males $(--\mathbf{\Delta}--)$, sample sizes were $1-3$, for all measures. For ovariectomized females $\left(--\bigcirc_{-}\right)$, sample sizes were 1-5 (a), 0-1 (b) and 1-5 (c). ***Intact female $>$ intact male, $P<0.001$; *intact male $>$ intact female, $P<0.05$; ${ }^{+}$intact female $>$ ovariectomized female, $P<0.0005$. 


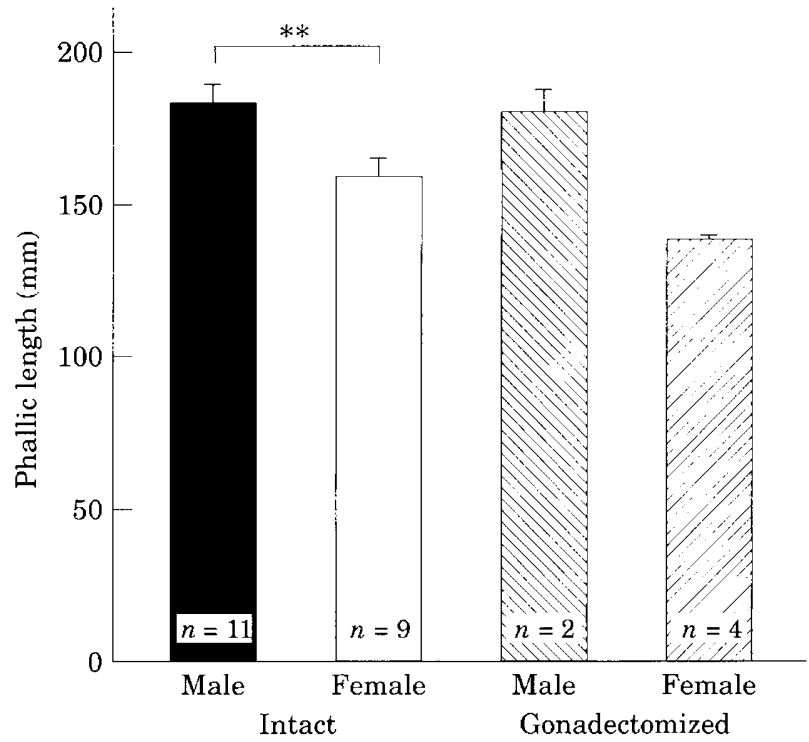

Fig. 2. Mean $\pm \operatorname{sem}$ phallic length of ( $\boldsymbol{\square}$ ) intact male, ( $\square$ ) intact female, $(\square)$ castrated male and $(\square)$ ovariectomized female spotted hyaenas, aged from 4 to 12 years. ${ }^{* *}$ Intact males $>$ intact females, $p<0.005$

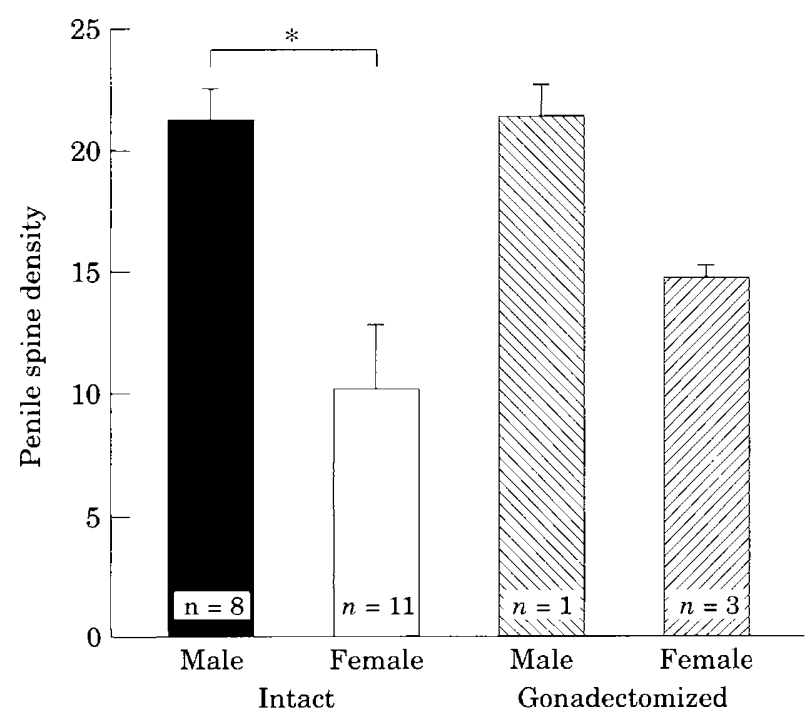

Fig. 3. Mean \pm SEM density of spines on the glans of ( $\boldsymbol{\square}$ ) intact male, $(\square)$ intact female, $(\mathbb{Q})$ castrated male and ( $(Z)$ ) ovariectomized female spotted hyaenas, aged from 4 to 12 years. Density represents the number of spines contained within a $36 \mathrm{~mm}^{2}$ patch. *Intact males $>$ intact females, $P<0.02$.

body length all displayed greater absolute growth during the juvenile period (from 3 to 13 months of age), than during a much longer period encompassing puberty (from 13 to 31 months of age). The increased plasma testosterone concentrations observed at birth decline rapidly during the first month of life and do not increase again until 16-20 months of age (Glickman et al., 1992). There is little circulating testosterone from 3 to 13 months of age and puberty is generally achieved in male spotted hyaenas between 18 and 24 months of age;
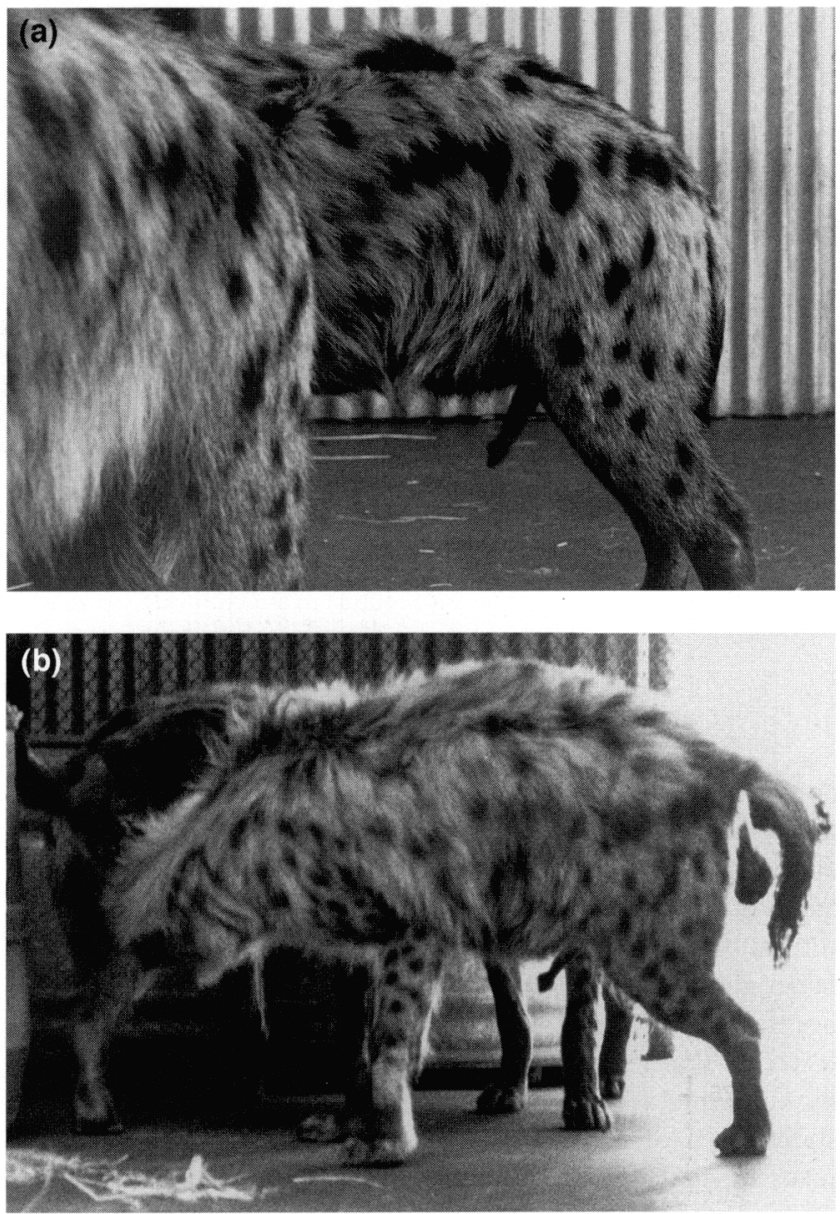

Fig. 4. Photographs of the erect penis of (a) a I-year-old male castrated at 37 days of age and (b) an 11-year-old male castrated at 6 months of age, both showing rigid erectile capability, as well as the angular contour normally observed in control males.

however, genital growth is virtually complete before the pubertal increase in testosterone concentration.

Kruuk (1972) has noted that the penis or clitoris of the infant hyaena is unusually well developed when compared with that of other mammals. This precocious development may be facilitated by the high concentrations of testosterone and androstenedione circulating in male and female fetuses during fetal and neonatal life. The results reported by Drea et al. (1998) on the effects of anti-androgens administered during fetal life offer some support for this hypothesis. However, there is also substantial penile and clitoral development in fetal hyaenas exposed to anti-androgens during the majority of the intra-uterine period.

The pattern of increase in clitoral length and body length in female hyaenas resembled that in males, in that the majority of growth was achieved well before puberty. However, whereas all measures of male genital development showed an early plateau, clitoral length and, particularly, clitoral glans diameter continued to increase after the first year. This period of growth coincides with the pubertal period (21-33 months of age), which is marked by an increment in plasma concentrations of oestrogen (Glickman et al., 1992). The elasticity of the urogenital meatus also shows a marked increment during this period in 

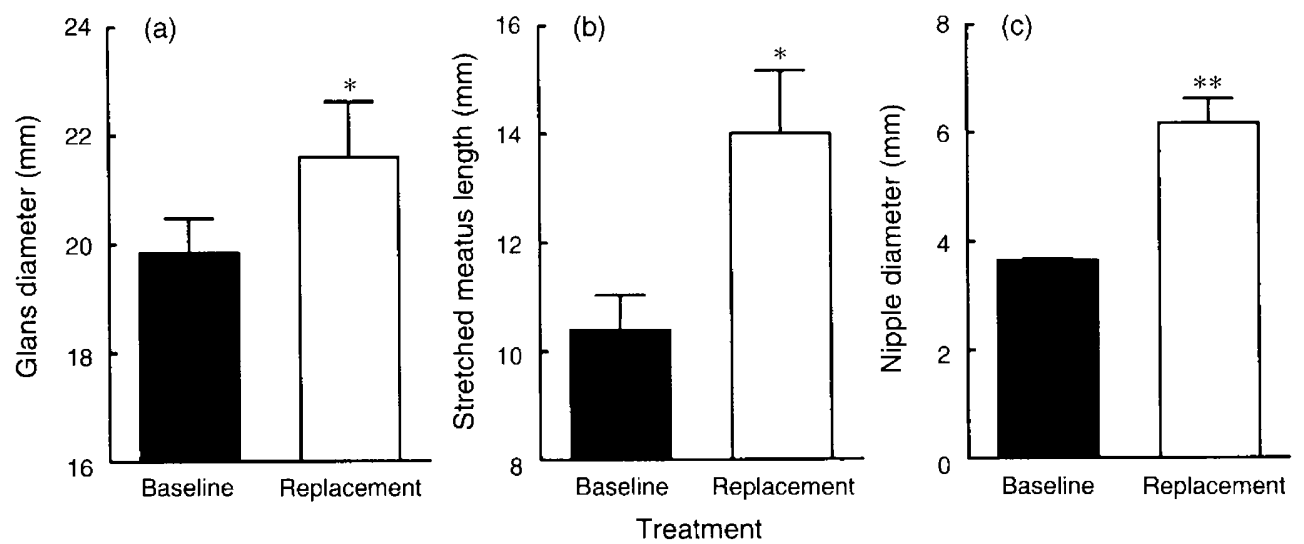

Fig. 5. Mean \pm SEM (a) clitoral glans diameter, (b) stretched length of the urogenital meatus and (c) nipple diameter in five adult ovariectomized spotted hyaenas, before ( $\boldsymbol{\square}$ ) and after 6 weeks of oestrogen replacement ( $\square$ ). *Oestradiol replacement $>$ pre-treatment baseline, $P<0.05$; ** replacement $>$ baseline, $P<0.005$.

normal female hyaenas (Glickman et al., 1992). Furthermore, ovariectomized females exposed to oestradiol show significant increases in glans diameter and length of the stretched urogenital meatus. Thus, it seems likely that pubertal acceleration of clitoral diameter and length of the urogenital meatus are due to oestrogen secretion, since these are female-typical characteristics that are not observed to accompany enhanced testosterone secretion during puberty in male hyaenas. Further evidence for this interpretation is provided by the finding that antiandrogen treatments during fetal life result in infants of both sexes having a thicker phallus and a larger urogenital meatus (Drea et al., 1998).

Prepubertal gonadectomy also had little apparent effect on hyaena penile morphology. In male dogs and rodents, prepubertal castration results in reduced genital growth and in fewer penile spines (Beach and Levinson, 1950; Beach and Westbrook, 1968; Beach, 1970, 1984; Sachs et al., 1984). By contrast, prepubertal gonadectomies of male and female hyaenas reduced neither the length of the developing phallus nor the density of spines on the glans. In the present study, the sample of castrated male hyaenas was limited to two animals, but the results are striking and consistent. In an animal castrated at 37 days of age, penile length at sexual maturity was still at the lower end of the normal male range. Furthermore, in a male castrated at 6 months of age, not only was penile length well within the normal male range, but the glans still showed a normal array of papillae and spines. It is possible that there are subtle effects of castration on penile morphology in the hyaena that could not be detected owing to the limitations of the sample size. For instance, penile spines in the animal examined more than 10 years after castration appeared thinner than those of intact animals and glans diameter was smaller than that of control subjects. In addition, there are probable effects of gonadectomy on sexual behaviour. This castrated male was never observed to mate despite nearly continuous housing with a female who was regularly impregnated by an intact male hyaena.

The data presented in this paper also suggest that prepubertal ovariectomy has minimal effects on clitoral length and the abundance of clitoral spines. However, there were substantial effects of ovariectomy on clitoral glans diameter or on elasticity of the urogenital meatus (Glickman et al., 1992). These are both female-typical morphological characteristics, and prepubertally ovariectomized females approximated males on these measures, showing reduced glans diameter and a urogenital meatus that did not stretch to normal female length. In this case, brief oestradiol treatment, many years after ovariectomy, partially restored the normal condition, suggesting that these female-typical traits are mediated by oestrogens.

Drea et al. (1998) demonstrated clear effects of anti-androgen treatment during fetal life on development of hyaena genitalia. However, these effects were limited to modifying penile and clitoral morphology in the feminine direction, when the normal sex differences in spotted hyaena genital morphology are used as points of reference. The present data indicate that, in terms of genital development, the actions of androgens are probably limited during postnatal life as well. The overall results suggest that the initial formation of the fetal phallus, and its subsequent growth during fetal and postnatal life, can proceed in a remarkably 'normal' (for a spotted hyaena) fashion without the influence of gonadal androgens. However, the divergence in phallic morphology between male and female hyaenas is, at least in part, modulated by the different hormonal environments experienced by the two sexes. The actions of testosterone during fetal life set a course for males that results in the species-typical form of the penis persisting and developing during postnatal life, even in castrated males. Castration reduces circulating concentrations of testosterone and androstenedione by more than $90 \%$ (Glickman et al., 1992), although possible facilitating effects of residual adrenal androgens on genital growth cannot be ruled out. In female spotted hyaenas, the actions of prenatal androgens also serve to modify the clitoris in the male direction (for example, reducing the size of the urogenital meatus), while postnatal effects of oestrogens, and possibly relaxin (Steinetz et al., 1997), promote a set of feminine characteristics that facilitate copulation and birth. Development of the external genitalia of spotted hyaenas involves the integrated action of androgens, other steroids and androgen-independent mechanisms. 
Spotted hyaenas have elaborate meeting ceremonies, during which the participants stand side-by-side, head-to-tail, and inspect the erect genitalia of the adjacent hyaena (Kruuk, 1972). Such ceremonies were a common daily occurrence in our colony, stimulated by socially 'exciting' events (for example, competitive feeding), or by temporary separation and reunion of individuals. During a study of effects of separation on participation in meeting ceremonies, male and female gonadectomized hyaenas displayed normal erections more than a year after gonadectomy (N. A. Krusko, M. L. Weldele and S. E Glickman, unpublished). Erections were also maintained by gonadectomized male and female hyaenas many years after surgery (Fig. 4). These results clearly indicate that the mechanisms underlying both the psychological stimuli inducing the erections associated with meeting ceremonies, and the actual neuromuscular genital reflexes are not dependent on gonadal androgens. However, both dogs (Beach, 1970, 1984) and rhesus monkeys (Goy, 1964) retain substantial erectile capability after prepubertal gonadectomy. Further long-term, comparative studies will be required to determine whether the exceptionally long-persisting erectile capabilities of prepubertally gonadectomized spotted hyaenas are genuinely different from other mammals.

East $e t$ al. (1993) emphasized the critical nature of participation in the hyaena meeting ceremony for integration of individual animals into their social group. Kruuk (1972) speculated that selection favoured development of the penile clitoris in this species because of the advantages conferred by such participation. Meeting ceremonies normally require an erect phallus and such ceremonies are frequent events throughout the life span of every spotted hyaena within its clan, beginning in the earliest months of infancy. It seems possible that this lifetime participation in meeting ceremonies was facilitated by the emergence of a mechanism that produced the basic phallic structure of the spotted hyaena without dependence on gonadal androgens.

The authors are indebted to the veterinary staff of the Office of Laboratory Animal Care on the Berkeley Campus, particularly D. Berger and D. DeNardo. This work was supported by Grant MH-39917 from the NIMH (to S. E. Glickman) and by National Research Service Award HD-07684 from the NIH to C. M. Drea.

\section{References}

Beach FA (1970) Coital behavior in dogs: VI. Long-term effects of castration upon mating in the male Journal of Comparative and Physiological Psychology 70 $1-32$

Beach FA (1984) Hormonal modulation of genital reflexes in male and masculinized female dogs Behavioral Neuroscience 98 325-332

Beach FA and Levinson G (1950) Effects of androgen on the glans penis and mating behavior of castrated male rats Journal of Experimental Zoology 114 159-168

Beach FA and Westbrook WH (1968) Dissociation of androgenic effect on sexual morphology and behavior in male rats Endocrinology 83 395-398
Drea CM, Weldele ML, Forger NG, Coscia EM, Frank LG, Licht P and Glickman SE (1998) Androgens and masculinization of genitalia in the spotted hyaena (Crocuta crocuta). 2. Effects of prenatal anti-androgens Journal of Reproduction and Fertility 113 117-127

East ML, Hofer $\mathrm{H}$ and Wickler W (1993) The erect 'penis' is a flag of submission in a female-dominated society: greetings in Serengeti spotted hyaenas Behavioral Ecology and Sociobiology 33 355-370

Frank LG and Glickman SE (1994) Giving birth through a penile clitoris: parturition and dystocia in the spotted hyaena (Crocuta crocuta) Journal of Zoology, London 234 659-690

Frank LG, Weldele ML and Glickman SE (1995) Masculinization costs in hyaenas Nature 377 584-585

Glickman SE, Frank LG, Davidson JM, Smith ER and Siiteri PK (1987) Androstenedione may organize or activate sex-reversed traits in female spotted hyaenas Proceedings of the National Academy of Sciences USA 84 3444-3447

Glickman SE, Frank LG, Pavgi S and Licht P (1992) Hormonal correlates of 'masculinization' in female spotted hyaenas (Crocuta crocuta). 1. Infancy to sexual maturity Journal of Reproduction and Fertility 95 451-462

Goy RW (1964) Reproductive behavior in mammals. In Human Reproduction and Sexual Behavior pp 409-411 Ed. CW Lloyd. Lea and Fibiger, Philadelphia, PA

Ioannou JM (1971) Female reproductive organs. In Comparative Reproduction of Nonhuman Primates pp 131-159 Ed. ESE Hafez. Charles C Thomas Publisher, Springfield, IL

Kruuk H (1972) The Spotted Hyaena University of Chicago Press, Chicago

Licht P, Frank LG, Pavgi S, Yalcinkaya TM, Siiteri PK and Glickman SE (1992) Hormonal correlates of 'masculinization' in female spotted hyaenas (Crocuta crocuta). 2. Maternal and fetal steroids Journal of Reproduction and Ferfility 95 463-474

Licht P, Hayes T, Tsai P-S, Cuhna G, Kim H-S, Golbus M, Hayward S, Martin MC, Jaffe RB and Glickman SE (1998) Androgens and masculinization of genitalia in the female spotted hyaena (Crocuta crocuta). 1. Urogenital morphology and placental androgen production during fetal life Journal of Reproduction and Fertility 113 105-116

Lindeque M and Skinner JD (1982) Fetal androgens and sexual mimicry in spotted hyaenas (Crocuta crocuta) Joumal of Reproduction and Fertility 65 405-410

Matthews LH (1939) Reproduction in the spotted hyaena, Crocuta crocuta (Erxleben) Philosophical Transactions of Royal Society London Series B 230 1-78

Neri RO, Florance K, Koziol P and Van Cleave S (1972) A biological profile of a non-steroidal anti-androgen, SCH 13521 (4'-nitro-3'-trifluoromethylisobutyranilide) Endocrinology 91 427-437

Neumann F, von Berswordt-Wallrabe R, Elger W, Steinbeck H, Hahn JD and Kramer M (1970) Aspects of androgen-dependent events as studied by anti-androgens Recent Progress in Hormone Research 26 337-405

Physicians' Desk Reference (1997) 51st Edn p 753 Medical Economics Company, Montvale, NJ

Plant TM (1988) Puberty in primates. In The Physiology of Reproduction pp 1763-1788 Eds E Knobil and J Neil. Raven Press, New York

Racey PA and Skinner JD (1979) Endocrine aspects of sexual mimicry in spotted hyaenas Crocuta crocuta. Journal of Zoology, London 187 315-326

Sachs BD, Glater GB and O'Hanlon JK (1984) Morphology of the erect glans penis in rats under various gonadal hormone conditions Anatomical Record $21045-52$

Schonfeld WA (1943) Primary and secondary sexual characteristics: study of their development in males from birth through maturity, with biometric study of penis and testes American Journal of Diseases of Children $65535-549$

Steinetz BG, Randolph C, Weldele M, Frank IG, Licht P and Glickman SE (1997) Pattern and source of relaxin secretion in the reproductive cycle of the spotted hyaena (Crocuta crocuta) Biology of Reproduction 56 130I-1306

Tanner JM (1978) Fetus into Man Harvard University Press, Cambridge, MA

Yalcinkaya TM, Siiteri PK, Vigne J-L, Licht P, Pavgi S, Frank LG and Glickman SE (1993) A mechanism for virilization of female spotted hyaenas in utero. Science 260 1929-1931 